\author{
Diljit Singh \\ Associate Professor \\ Faculty of Computer Science \& Information Technology \\ University of Malaya \\ Malaysia
}

\begin{abstract}
Technology offers great potential but can also create inequities and problems. One such inequity is the digital divide. The digital divide refers to the gap between those who can effectively use new information and communication tools, such as the Internet, and those who cannot. Those who are on the less fortunate side of the divide lose out in education, training, shopping, entertainment and communications opportunities. The causes of the digital divide are numerous, and include costs, access problems, lack of skills, cultural issues, and personal factors. As a result, reducing the digital divide needs to take a multi-faceted approach, which includes creating awareness and promotion, facilitating access, developing necessary skills, providing reliable support, developing suitable content, and ensuring community involvement. The mission of school libraries is threatened as long as the digital divide exists, and it is important that school libraries take steps to reduce this divide. These steps should include the approaches mentioned earlier, as well as using coordinated national, regional or local strategies, and collaborating with other organizations.
\end{abstract}

\title{
The Growth and Promise of Technology
}

Technological developments offer so many promises of a better life, while at the same time they create unforeseen inequities and problems. One of these inequities that has emerged is the "digital divide". The digital divide refers to the gap between families, organizations, regions, and nations at different socio-economic levels, in the opportunities and abilities to access information and communication technologies and to the use of information for a variety of activities. The problem is serious enough to warrant literally hundreds of reports, surveys, commentaries, and initiatives at the local, national and international levels. This paper argues that school libraries also have an important role to play in reducing the digital divide.

Today, we find ourselves in the best of times and in the worst of times. The development and convergence of several technologies, including computers, multimedia, telecommunications, the Internet and the World Wide Web, have brought us quantum leaps closer to being able to deliver on the promise of technology to re-shape our entire culture. Never before have we had so much real potential to fully exploit the capabilities of the new technologies. We see real evidence around us every day that the technological developments are actually changing our lives (Rogers, 1996).

The potential of technology is indeed immense. This potential can be summed up in the 5 I's - Information, Interaction, Interactivity, Individualization, and Increased access. Technology has the potential to provide an increased quantity, better quality, and current information. It can provide enhanced interaction between the teachers and the learners, and among learners, leading to a borderless learning community. Technology encourages greater interactivity in the learner's engagement with content, especially in constructing relationships, and relating new knowledge to existing structures. Technology allows for greater individualization in customization for flexibility and personal attention, and personalization through the learner's choice of pace, interface, and navigational direction. Technology also allows increased access, free from constraints of time, place, teacher, various -isms, and allows for life long learning (Pan, no date).

Yet, technology has also created many problems, one of them being the digital divide. 


\section{The Digital Divide}

The term "digital divide" came to public attention after a 1995 study by the Markle Foundation revealed that the same divergence found in society along cultural and racial lines, was found online and offline too. Lloyd Morrisett, the former president of the Markle Foundation, called it a digital divide between the information 'haves' and 'have-nots'. These findings have been subsequently supported by other studies (Stoicheva, 2000).

The digital divide has many definitions. One frequently used definition characterizes it as "differences due to geography, race, economic status, gender, and physical ability in access to information through the Internet and other information technologies and services, and in the skills, knowledge, and abilities to use information, the Internet and other technologies" (American Library Association, 2001).

There are many other definitions of the digital divide, which focus on various elements of information and communication technology (ICT) and its usage. Bridges.org, an international organization working to span the digital divide through policy initiatives and ground-level projects, lists five different perspectives on the digital divide (Bridges.org, 2001):

- the digital divide is a lack of physical connections and training - computer hardware, network access, and (in some arguments) training, is required to bridge the digital divide, and governments, NGOs and private initiatives should supply them;

- the digital divide is a lack of computers, access and training, but the problem will solve itself in time computer hardware and network access are required, but the market and selective development projects will solve this problem on its own by steadily lowering prices, fostering an IT training sector, and extending infrastructure to outlying regions;

- the digital divide is a lack of computers, access and training, exacerbated by ineffective government policy government actions (or inaction) hinder the development and use of computers, and until these policies are changed the digital divide cannot be resolved;

- the digital divide is a lost opportunity, with disadvantaged groups being unable to effectively take advantage of ICT to improve their lives - what really matters is how the technology is used, and its potential to improve the quality of life for disadvantaged groups; effective use requires computers, connections, training, locally relevant content, and real applications of technology to fit immediate needs.

- the digital divide is a reflection of the lack of basic literacy, poverty, health and other social issues - computers are useful, but nothing will enable a society to bridge the digital divide until basic literacy, poverty, and healthcare issues are addressed.

There are many misconceptions about the digital divide too. For example, the digital divide is often looked at just as a lack of computers and connections. Yet, it is a social problem that is caused, in part, by inequities in the ability to access and to use information communication technologies. As this problem impacts the opportunities for participation in social and economic activities, the digital divide needs to be seen as a threat to social and economic justice (Mitchell, 2001). Reducing the digital divide can help people to achieve their potential, promote sustainable economic and social development, and basically improve their quality of life.

There is also a misconception that the digital divide is a rich country-poor country issue. Although the scope of the digital divide is global, the divide is not between countries only; it also exists within a country, and even within cities. Even within advanced countries like the United States, there are findings of a serious and growing digital divide in communities, in the workforce, and especially in the classrooms, that are quickly marginalizing entire segments of the American population (Foster, 2001). There are disparities within countries based on race, income, geographical location, educational levels, age, gender, and disabilities. 


\section{Implications of the Digital Divide}

The implications of the digital divide are far-reaching. The National Telecommunications and Information Administration [NTIA] (2002) summarizes it very succinctly:

To be on the less fortunate side of the divide means that there is less opportunity to take part in our new informationbased economy, in which many more jobs will be related to computers. It also means that there is less opportunity to take part in the education, training, shopping, entertainment and communications opportunities that are available online.

In many cases, even though the technology is available, people do not use it because either they do not understand it, they are uncomfortable using it, they cannot afford it, or they cannot see its utility. For them the digital divide means lost opportunities - opportunities to offer better educational tools and courseware to school children, opportunities to use information tools to bring medical applications to rural villages, opportunities to give local businesses access to global markets, or opportunities to make governments more effective and efficient (Bridges.org, 2001). Being on the less fortunate side of the digital divide also affects business. Business leaders are just as concerned about the digital divide, not only because it hampers business-to-business (B2B) activities but also because consumers are denied access to the Internet, making it difficult for them to participate in business to consumer (B2C) level electronic commerce (Gaillard, 2001).

There is evidence of a close association between ICT use and per capita national income, underlying the lost opportunities for economic growth among those unable or not using information technology. This is reinforced by the finding (from OECD countries) that multi-factor productivity growth is positively associated with ICT use (International Labour Review, 2001). The long-term stability of national economies and international markets is also at risk, particularly if the current trends of the "brain drain" continue to draw people out of developing countries that are on the less fortunate side of the digital divide, towards areas with better promises of economic prosperity.

\section{Causes of the Digital Divide}

In recent years, there have been many studies and analyses on the causes of the digital divide. These studies have ranged from detailed empirical studies of the nature and scope of the divide to popular articles looking at the general nature and growth of the divide. Most analyses have been driven by two key objectives: firstly, a desire to identify the extent and nature of the digital divide and secondly, a desire to identify policy prescriptions to narrow the digital divide. A clear understanding of the underlying causes of the digital divide is necessary for the development of appropriate policies that will be effective in narrowing the digital divide. Inadequate attention to the underlying causes of the digital divide means that there is a risk that the policies will be implemented but will not always attain their desired goals (Wijewardena, 2002).

From these studies and analyses, many reasons have emerged as to why a significant proportion of the population cannot, or does not, make full use of the Internet and ICT in general. However, no single, simple cause has been identified for the digital divide. Instead there are many factors, which have been grouped and organized in various ways. One classification (Darlington, 2002) categorizes the causes into the lack of 5 C's - connectivity, convenience, cost, cash, confidence, and culture, and $1 \mathrm{Y}$ - why. These factors can be further expanded to 9 C's:

- Connectivity - the need for an access device and a connection to the Internet,

- Capability - the need for knowledge and skills to make use of the technology,

- Content - the need for material to meet the user's needs,

- Cause - the need for a compelling reason to use the technology,

- Cost - the initial and continuing costs of connection and usage,

- Convenience - the ability to use the technology at a time and place that is appropriate, more so by the less-able or disadvantaged users,

- Confidence - the need for users to be confident in using the technology, not to fear what they, or their children, will encounter, and also, the need for security and privacy when making financial transactions,

- Cash/Credit Cards - the need for cash cards and or credit cards, especially when making financial transactions,

- Culture - the norms of society where information is valued and used. 
All these factors affect the use information and communications technology, and the absence of one or more of these can result in the digital divide.

These factors apply to varying degrees in many parts of the world. A Scottish official document (Scottish Executive, 2001) summarizes the causes of the digital divide as:

- Perceived or Actual Costs - the perceived or actual cost of PCs and other equipment, and the perceived or actual cost of web-related telephone calls,

- Access - the lack of near-by/affordable facilities providing access to the Web/ICT, and the lack of work-related access to ICT and the Web to build skills and awareness,

- Skills - the lack of literacy and numeracy skills, ICT skills, and the lack of knowledge/appreciation of the information and services that can be found on the Web,

- Cultural Issues - the lack of a critical mass of other Web/PC users among community/ family/friends, and other cultural barriers, and

- Personal Factors - such as the lack of confidence, lack of credit card/bank account, a fear of technology, a feeling it is too late in life to learn about new technologies, no interest in the Internet, physical difficulties such as poor eyesight or manual dexterity and co-ordination.

Interactions among these factors also probably play a part too. In one study in the United States, it was noted that there were some major social (internal) components behind African American students' reluctance to use technology, which resulted in failure to integrate computer technology into their daily lives. The study found significant differences in computer self-efficacy, and at-task time between groups when analyzed on the basis of race and gender (Foster, 2001).

A section of the Technology Counts 2001: The New Divides, identifies the kinds of students who appear to be losing out when it comes to technology. For a variety of reasons, those students include poor children, minority students, girls, low achievers, students learning to speak English, children with disabilities, and youngsters who live in rural areas. This coincides with findings within the National Technology Readiness Survey (NTRS) suggesting that education transcended Internet access as a major factor contributing to the digital divide.

It is therefore important to keep in mind that while the hardware, access and connectivity are important factors, the digital divide is not just about a lack of access to computers and information technology. Many factors come into play, and this should be recognized in efforts to reduce the digital divide.

\section{Reducing the Digital Divide}

Knowing the disadvantages and causes of the digital divide, it is then imperative that efforts be taken to minimize or at least reduce the digital divide. Various factors need to be taken into consideration in these efforts.

For a start, policies and programs need to incorporate a broader 'social vision' for lifelong learning rather than just giving people computers and providing basic skills. One study indicates a positive correlation between the use of Internet technologies and variables such as organization size, assets, IT investment, IT personnel, and history of innovation adoption (Zimmer, 2001). All these need to be given attention.

Various strategies, approaches and proposals have been put forward and can be used to reduce this digital divide, some narrowly focused and some broad-based.

Narrowly focused programs can have a small but significant impact. For example, a project called "Unwiring the World" uses a simple solution to provide access to $21^{\text {st }}$ century technology in a remote Central American jungle. Founded in 1998 by Alex Pentland, of the MIT Media Lab, and Jose Maria Figueres, former president of Costa Rica, Unwiring the 
World is creating portable digital town centers: recycled shipping containers furnished with telemedicine units, cash machines, micro computer schools, soil-and-environment testing labs, FM radio stations, wireless satellite links, and bigscreen televisions. Seven of the units, dubbed LINCOS, or little intelligent communities, have been installed in off-the-grid areas in Costa Rica and the Dominican Republic, where they are being used by residents to help form agricultural cooperatives, launch e-commerce initiatives, and access education and employment information online (Schwartz, 2001).

On a broader scale, the Scottish document, Digital Inclusion (Scottish Executive, 2001) summarizes the types of actions that need to be taken to overcome the digital divide. These actions can be categorized as;

- Awareness and Promotion - it is essential that we ensure excluded individuals and groups are aware of the opportunities that ICT can provide,

- Access - all people, but particularly disadvantaged individuals and communities, must have access to ICT at the time, place, method and price appropriate to their needs and lifestyles,

- Support - providing reliable, accessible and cost-effective sources of advice and support is crucial,

- Skills - we need to provide the basic computer and technological skills that will instill individuals with the confidence to use ICT,

- Content - we must ensure that disadvantaged individuals and communities are provided with, or develop themselves, online content and services that they value and wish to use,

- Community Involvement - we need to make sure that the initiatives are sustainable at a local level, and that local communities have a sense of ownership.

Libraries are well suited to helping address the digital divide. Libraries have provided and continue to provide a full range of tools. Librarians act as information navigators who help people find the information they need and want, and provide a variety of educational experiences to support lifelong learning. Four of the essential tools required to bridge the digital divide are readily available through the library, including

- Literacy - the foundation for all information use

- Access - to free public information

- Training - to empower individuals to find and use information effectively, and

- Content - the rich source material that is needed to make the Internet a powerful information resource (Web Wise 2001).

This statement is supported in many places internationally. For example, in New Zealand, LIANZA/TRW advocates the process of tackling the digital divide must recognize that a key access outside of the home should be through the public library and school library networks. There also needs to be formal recognition of information literacy as an essential skill in a knowledge society. This needs to be reflected in the training of teachers and in recognition of the role public and school libraries play in this training process (LIANZA, 2001).

In the United States, libraries are helping to bridge the digital divide. Libraries have provided information access and services in the United States (US) for more than 100 years. Most libraries have the technical infrastructure, electronic resources and existing facilities. More than $90 \%$ of public library outlets [in the US] offer public access to the Internet and other electronic resources. Librarians are trained professionals who assist and instruct patrons (American Library Association, 2001). 


\section{The Role of School Libraries in Reducing the Digital Divide}

School libraries and their services are vital to the development of a literate population that is able to participate fully in a thriving society, democracy, culture, and economy. The school library provides information and ideas that are fundamental to functioning successfully in today's information and knowledge-based society. The school library equips students with life-long learning skills and develops the imagination, enabling them to live as responsible citizens (IFLA/UNESCO, 1999).

The digital divide is a significant barrier to fulfilling this mission. As long as there are inequities in access and use of information technology, the mission will not be fully accomplished.

School libraries can play an important role in reducing the digital divide. They have a number of advantages and early starts, including:

- School libraries have a long history of instruction,

- School libraries have a captive audience,

- School librarians often enjoy close working relationships with teachers and the community,

- School librarians often have a teaching background,

- School libraries often have computers available that ensure basic technology access and skills.

As such they can, and should, take a wide range of steps to address the digital divide. These steps need to address the root causes of the digital divide - the lack of awareness, access, skills, appropriate content, and culture. Using the Scottish framework mentioned above (Scottish Executive, 2001) of creating awareness and promotion, ensuring access, providing reliable support, ensuring necessary skills are available, providing relevant content, and ensuring community involvement, school libraries can apply these approaches to their own specific situation and context.

- Creating awareness and promotion - school libraries have a captive audience of students and teachers who use the library frequently. School libraries also frequently carry out publicity campaigns, from the use of simple bulletin boards to sophisticated staged events. It is therefore not difficult for school libraries to create an awareness of the importance of ICT among the school population. But school libraries must go beyond just creating awareness. They must generate a genuine and lasting interest in using ICT. They must also ensure that disadvantaged children are aware of the opportunities that ICT can provide, and are encouraged or provided with incentives to take advantage of it.

- Providing access and connectivity - school libraries have traditionally provided facilities that were too costly or not practical for individuals to acquire. The provision of ICT follows similar lines, whereby school libraries can ensure that at least a small number of functional computers are available, and a system exists that allows every teacher and child to use the technology. Schools libraries must strive towards ensuring maximum access and connectivity for students and teachers. They need to make sure that barriers and constraints are removed, or at least minimized, for all. They need to make sure that the disadvantaged children have access to ICT at the time, place and method appropriate to their needs and lifestyles. This access does not need to be state of the art basic computers with a dial-up modem are often sufficient. The lack of computers and connections is often a challenge, especially for schools in the rural areas. This can be overcome with a coordinated effort, such as a large-scale donation system of used computers, functioning and non-functioning, similar to the California-based Computer Recycling Center. This would help reduce the problem of a lack of tools by providing rural schools and communities with equipment donated by homes and businesses. The non-functioning computers donated could be used for parts to repair other computers or to teach students how to repair them and their components. Functional computers could be immediately shipped to schools and computer workshops, where students and teachers can use them. There can also be centers set up throughout the nation, where the donated computers would be gathered and packed. A software-donating component could also be incorporated into this plan. Floppies for Kiddies, a company in the United States that accepts donated software can serve as a model for this idea. Steps like these can be initiated by NGOs or even by the government to help solve this portion of the problem. 
- Ensuring necessary skills - sometimes a lack of access to technology may not be the only problem. Regardless of the level of access, teachers and students may not have sufficient training and knowledge to use the technology and make the most of the equipment available within the school. The purpose of using ICT is not to make a programmer out of everyone. Using technology is about enabling ordinary teachers and students to use ICT to make a real difference in their lives, and especially in their teaching-learning. To do this they need basic computer and technological skills that will instill in them the confidence to use ICT and the Web efficiently and effectively. School libraries can provide the opportunities to develop these skills through formal and informal training programs.

- Providing reliable support - it is not enough to just provide computers and connections, with training; reliable support is also necessary. Teachers and students need to have someone to turn to when having difficulties or problems, and technology needs to be attended to quickly when it is not functioning. Without support, teachers and students can lose interest or, worse, be too afraid even to experiment with technology. Providing reliable and accessible sources of advice and support on ICT and the Web is essential. Again, the school library can arrange for this support through trained teachers and students.

- Providing relevant content - the school community will be more inclined to use ICT if they see it as being something worth their time and effort. Students and teachers must thus have access to, or develop themselves, online content and services that they value and wish to use. School libraries, for example, can create websites and link to services providing local information. They can also provide information that is directly relevant to the teaching-learning of students and teachers. Developing content does not require sophisticated resources and high level skills; simple software skills and free hosting services can provide much local and relevant content.

In addition to the strategies and goals mentioned above, other approaches can also be considered.

- National, regional and local strategies - coordinated efforts are needed at the national, regional and local levels to reduce this divide. There are times where local efforts by schools must be complemented by national or regional/state policies and programs. Ensuring basic infrastructure, such as availability of electricity and telephone lines at reasonable rates, is a pre-requisite but must be done at the state or national level. Federal or state governments can introduce policies that would allocate a portion of the federal or state taxes imposed on large companies to specifically go towards the development of computer access. This can be done at existing centers (schools, libraries, community centers) in low-income and rural areas that otherwise would not have little or no computer access. The communities would have to come together to ensure the passing of these policies, and it would require "national technology literacy" coalitions dedicated in teaching the underprivileged public. Another idea would be for the government to create an incentive in order for these companies to provide computers and Internet access to these neighborhoods. Providing tax relief, even a fraction of a percentage point, or dropping some tax demands by the government on companies could help provide the necessary facilities.

- Collaboration - it is often difficult for school libraries to attain the goals alone, as they are usually limited in staff and financial resources. As such there is a need for collaborative efforts with other schools, parent-teacher associations, school library associations, businesses, non-governmental organizations, and any other organization that is in a position to help. In areas where the schools are too small to provide cost-effective access and connectivity, school libraries can take the initiative to collaborate with public libraries (where available) or community centers to provide computer access to the students. For example in Boston [USA], there exist Computer Clubhouses which are used for children in inner cities to have the access to computers and programs whenever they need or want to. They have mentors to help the children learn how to use different programs as well as learning basic computer skills. The mentors are high school and college students as well as professionals that volunteer their time at the clubhouse. The children are also encouraged to work together, in groups, to help each other learn. Programs modeled after these clubhouses can be beneficial to many rural areas by offering people the freedom to learn at their own pace in an environment where they will feel comfortable exploring new ideas. 
School libraries can carry out various other projects to attain these goals. Projects and initiatives that combine access skills, developing relevant content and community involvement are likely to be more effective - each reinforcing the benefits achieved by the other.

\section{Conclusion}

The digital divide is a reality. The divide is more than just a lack of computers; it is a social problem and it is a global phenomenon, which can lead to even more problems if it gets wider. Those who are on the fortunate side of the divide may not feel the effects of it, but like any other social problem, the digital divide needs to be addressed before it gets worse. We need to wage a war on the digital divide, and school libraries must be a key element in that war.

\section{References}

American Library Association, Office for Information Technology Policy. (2001). What is the digital divide? Retrieved March 15, 2003 from http://www.ala.org/oitp/digitaldivide/what.html

Bridges.org (2001). Spanning the digital divide: Understanding and tackling the issues. Annex 1. Perspectives on the Digital Divide. Retrieved March 15, 2003 from http://www.bridges.org/spanning/annex1.html

Foster, Jesse J. (2001). Self-efficacy, African-American youth, and technology: Why the belief that 'I cannot do that' is driving the digital divide. Unpublished doctoral dissertation, University of Alabama.

Darlington, Roger. (2002). Overcoming the digital divide: Internauts and Internots. Retrieved March 16, 2002 from http://www.rogerdarlington.co.uk/digitaldivide.html

Gaillard, Franklin D. (2001). Understanding the digital divide as it relates to electronic commerce. Unpublished doctoral dissertation, Old Dominion University.

IFLA/UNESCO (1999). School Library Manifesto: The school library in teaching and learning for all. The Hague: International Federation of Library Associations and Institutions.

International Labour Review (2001). The digital divide: Employment and development implications. Retrieved March 16, 2003 from http://www.ilo.org/public/english/support/publ/revue/download/pdf/intro012.pdf

LIANZA / TRW [Library and Information Association of New Zealand and TeRoopuu Whakahau, Maori Library and Information Workers Association.] (2001). ... towards a knowledge society: National information strategy [pamphlet].

Mitchell, Matthew M. (2001). Exploring the future of the digital divide through ethnographic futures research. Unpublished doctoral dissertation, Gonzaga University.

National Telecommunications and Information Administration, U S Department of Commerce (2002). A nation online: How Americans are expanding their use of the Internet. Retrieved March 15, 2003 from http://www.ntia.doc.gov/ntiahome/dn/index.html

Pan, Daphne (no date). e-Education: Delivering the promise of technology. Center for Development of Teaching and Learning, National University of Singapore. Retrieved March 14, 2003 from http://www.cdtl.nus.edu.sg/eed/cdtl files/frame.htm

Rogers, Al. (1996). The failure and the promise of technology in education. Retrieved March 14, 2003 from http://www.gsn.org/teach/articles/promise.html

Schwartz, Bonnie. (2001). Unwiring the world: Small, intelligent communities are working to combat the digital divide. Retrieved March 14, 2003 from http://www.fastcompany.com/online/43/lookfeel.html 
Stock, Elisabeth. (no date) Computers for Youth; Focusing Digital Efforts on the Home. Retrieved March 15, 2003 from http://www.digitaldividenetwork.org/content/stories/index.cfm?key=107

Stoicheva, Mila. (2000). The Digital Divide and Its Implications for the Language Arts. ERIC Digest D153. ED442138

Technology Counts 2001: The New Divides, looking beneath the numbers to reveal digital inequities. Education Week, 20 (35), May 10, 2001.

Web Wise (2001). [Conference Program] The digital divide: A conference on libraries and museums in the digital world. Retrieved March 15, 2003 from http://www.imls.gov/pubs/pdf/pubwbws01.pdf

Wijewardena, Madura. (2002). Assessment of existing empirical analyses of the underlying causes of the digital divide and policy prescriptions to deal with such underlying causes of the digital divide - ideas for policy makers.

Communications Research Forum. Retrieved March 14, 2003 from

http://www.gtlaw.com.au/templates/employee/list publications 2.jsp?team id=177\&empname=Madura\%20Wijewardena

Zimmer, Eric A. (2001). For to all those who have, more will be given: The Matthew effect, nonprofit organizations, and the adoption of Internet technologies. Unpublished doctoral dissertation, University of Pennsylvania.

\section{Author Note}

Diljit Singh graduated with a B.Sc. from the University of Malaya, Kuala Lumpur, and an M.S. and Ph.D. from Florida State University, USA. He taught in two schools, and worked at the state and federal levels of the Ministry of Education Malaysia before joining the university. Diljit is currently an Associate Professor at the Faculty of Computer Science and Information Technology, University of Malaya, 50603 Kuala Lumpur, Malaysia. He is also a past Director for Asia, International Association of School Librarianship. E-mail: diljit@um.edu.my

\section{Appendix}

\section{Selected Resources on the Digital Divide}

These resources represent a small sample of resources available on the Internet related to the Digital Divide. Selection is based on regularly updated sites, and those that have international applications, rather than country-specific applications.

Bridges.org http://www.bridges.org/digitaldivide/index.html is an international non-profit organization with a mission to help people in developing countries use information and communications technology to improve their lives. It has a well thought out web site on the digital divide.

Digital Divide Network http://digitaldividenetwork.org/content/sections/index.cfm examines the digital divide from many perspectives. The web site offers a range of information, tools and resources that help practitioners stay current on digital divide developments. It also serves as forum where practitioners can share their experiences with colleagues around the world.

Digital Inclusion http://www.scotland.gov.uk/library3/enterprise/dics-00.asp is a brief but comprehensive Scottish Executive document on the need for a digitally inclusive society - where all can play their part in new ways to strengthen communities and where each individual can gain the benefits of being online.

Digital Opportunity Task Force www.dotforce.org/ is a report of the G8 Digital Opportunities Task (DOT) Force that outlines how governments, businesses and civil society can work together to advance human development and reduce poverty through the use of information and communications technologies.

UNESCO Observatory Portal: Digital Divide - International Positions

http://www.unesco.org/webworld/portal observatory/Access - Applications/ Digital Divide/International Positions/index.shtml provides useful links to resources on the digital divide. 